only loss of credibility for medical bodies. Driving a car, crossing a road, moving into a new relationship, let alone taking aspirin or a tricyclic antidepressant, are all dangerous, but we balance the risk with the benefit. No doubt all the reported effects of cannabis are correctly documented. But only those who can see no benefit in cannabis seem to pounce on another piece of information to confirm what they already know to be true, that cannabis really is a deadly drug. The rest of us get along with a pragmatic, balanced view.

Ashton, C. H. (200I) Pharmacology and effects of cannabis: a brief review. British Journal of Psychiatry, 178, 101-106.

Johns, A. (200I) Psychiatric effects of cannabis. British Journal of Psychiatry, 178, 116-122.

MacCoun, R. \& Reuter, P. (200I) Evaluating alternative cannabis regimes. British journal of Psychiatry, 178, 123-128.

Peele, S. (1990) Addiction as a cultural concept. Annals of the New York Academy of Sciences, 602, 205-220.

Robson, P. (200I) Therapeutic aspects of cannabis and cannabinoids. British Journal of Psychiatry, 178, 107-115.

Tanda, G., Munzar, P. \& Goldberg, S. R. (2000) Selfadministration behavior is maintained by the psychoactive ingredient of marijuana in squirrel monkeys. Nature Neuroscience, 3, 1073-1074.

A. R. MacQueen Clinical Services Building, Bloomfield Hospital, Forest Road, Orange 2800, Australia

\section{Future of mental health services in Kosovo}

Transformation of hospital-based mental health care has been widely discussed in post-communist countries. However, there are still doubts about the efficiency of community-based care, particularly because of hospital- and drug-based traditions.

We worked between October 1999 and July 2000 as medical doctors in community shelters in Peje, Kosovo with a Czech Republic non-governmental organisation, 'People in Need'. We found that the conflict in Kosovo brought an opportunity to review the whole approach of the mental health system.

During the 1990s many Albanian physicians had been fired from jobs at public hospitals. Kosovo Albanians were often forced to seek medical care in private institutions or turn to humanitarian agencies. In May 1999, most of the Serbian minority left Kosovo, including medical staff. International institutions are now working with local doctors to fill the gap in the health care system. Kosovo, with a population of 1.8 million, had only approximately 25 psychiatrists (July 2000). Medication and hospitalisation are the only tools professionals use to deal with psychiatric disorders. The same doctors usually provide neurological and psychiatric care.

Despite this situation, the future mental health services in Kosovo will be oriented towards a community-based approach. World Health Organization adviser Liliana Urbina considers this model not only more humane but also more cost-effective and more affordable for local conditions (L. Urbina, personal communication, 2001). Community-based mental health centres are planned to organise day hospital and out-patient care, individual and group therapeutic activities, manage sheltered accommodation and a psychiatric ward for those with acute psychiatric disorders (one bed per 16 000-18 000 population). The team of 20 professionals will respond to the mental health needs of 250 000-350 000 inhabitants.

Local doctors are now being offered training in places where the concept of community-oriented psychiatry is developing such as Trieste (Italy), Asturias (Spain) and Birmingham (UK). Although local staff, who had to deal with hundreds of international organisations, often suffered from "mission fatigue" (Black \& Tosic, 1999), they seem to be attracted by this concept.

Black, M. E. \& Tosic, O. (1999) Mental health of refugees from Kosovo. Lancet, 354, 165-166.

J.Vevera, D. Pohlraich Psychiatric Clinic, Ist Medical Faculty, Charles University of Prague, Czech Republic Institute of Hematology and Blood

Transfusion, Prague, Czech Republic

\section{Suicide prevention: service contacts and coordination between primary and secondary care}

Eagles et al (2001) emphasise the problems inherent in the psychiatrist's role with regard to suicide prevention. We sympathise with their view that unrealistic expectations may lead to psychiatrists being unfairly criticised. Nevertheless, it would be a pity if we were to lose enthusiasm, without good reason, for engaging in the challenge of suicide prevention.

In quoting our paper (Vassilas \& Morgan, 1993), Eagles et al refer to our finding that younger suicides (aged $<35$ years) had a relatively low general practitioner (GP) contact rate $(20 \%)$ in the last month before they died. However, it is also important to realise that the contact rate varied greatly between subgroups of our sample. For instance, $52 \%$ of older suicides made such contact, and more specifically $68 \%$ of those over 65 years of age did so (Vassilas \& Morgan, 1994). In a later paper (Vassilas \& Morgan, 1997) we showed that $39 \%$ of all males and $76 \%$ of all females made contact with any service within the last month of their lives. This index concerned contact with either primary or secondary services rather than just with mental health services, which is the criterion used by Appleby et al (1999). Our wider index of contact presents a more encouraging, yet we believe realistic, view of our potential role in suicide prevention.

It is clear that in practice it can be difficult to coordinate primary and secondary care, but close collaboration between psychiatrist and GP, with regard to the assessment and management of suicide risk, surely warrants special attention in our attempts to become more effective in suicide prevention. The acquisition of relevant clinical skills is, as Eagles et al points out, as crucial as the epidemiological approach in this field.

Appleby, L., Shaw, J., Amos, T., et al (1999) Suicide within 12 months of contact with mental health services national clinical survey. BMJ, 318, 1235-1239.

Eagles, J. M., Klein, S., Gray, N. M., et al (2001) Role of psychiatrists in the prediction and prevention of suicide: a perspective from north-east Scotland. British Journal of Psychiatry, I78, 494-496.

Vassilas, C. A. \& Morgan, H. G. (1993) Genera practitioners' contact with victims of suicide. BMJ, $\mathbf{3 0 7}$ 300-301.

_ \& _ (1994) Elderly suicides' contacts with their general practitioner before death. International journal of Geriatric Psychiatry, 9, 1008-1009.

_ \& _ (1997) Suicide in Avon. Life stress, alcohol misuse and use of services. British journals of Psychiatry, 170, 453-455

C.Vassilas Queen Elizabeth Psychiatric Hospital, Mindelsohn Way, Edgebaston, Birmingham BSI5 2QZ, UK

H. G. Morgan University of Bristol, Bristol, UK 